Article

\title{
A Novel Synergistic Flame Retardant of Hexaphenoxycyclotriphosphazene for Epoxy Resin
}

\author{
Jiawei Jiang ${ }^{1,2}$, Siqi Huo ${ }^{1}{ }^{\oplus}$, Yi Zheng ${ }^{1}$, Chengyun Yang ${ }^{1}$, Hongqiang Yan ${ }^{1, *}$, Shiya Ran ${ }^{1, *}$ and Zhengping Fang ${ }^{1}$ \\ 1 Laboratory of Polymer Materials and Engineering, NingboTech University, Ningbo 315100, China; \\ 714413862@163.com (J.J.); sqhuo@nbt.edu.cn (S.H.); zy13357018173zy@163.com (Y.Z.); \\ yangchengyun991007@163.com (C.Y.); zpfang@nbt.edu.cn (Z.F.) \\ 2 College of Chemical and Biological Engineering, Zhejiang University, Hangzhou 310027, China \\ * Correspondence: yanhongqiang@nbt.edu.cn (H.Y.); ranshiya@nbt.edu.cn (S.R.)
}

check for updates

Citation: Jiang, J.; Huo, S.; Zheng, Y.; Yang, C.; Yan, H.; Ran, S.; Fang, Z. A Novel Synergistic Flame Retardant of Hexaphenoxycyclotriphosphazene for Epoxy Resin. Polymers 2021, 13, 3648. https://doi.org/10.3390/ polym 13213648

Academic Editor: Emin Bayraktar

Received: 28 September 2021

Accepted: 18 October 2021

Published: 23 October 202

Publisher's Note: MDPI stays neutral with regard to jurisdictional claims in published maps and institutional affiliations.

Copyright: (c) 2021 by the authors. Licensee MDPI, Basel, Switzerland. This article is an open access article distributed under the terms and conditions of the Creative Commons Attribution (CC BY) license (https:// creativecommons.org/licenses/by/ $4.0 /)$

\begin{abstract}
Hexaphenoxycyclotriphosphazene (HPCP) is a common flame retardant for epoxy resin (EP). To improve the thermostability and fire safety of HPCP-containing EP, we combined $\mathrm{UiO} 66-\mathrm{NH}_{2}$ (a kind of metal-organic frame, MOF) with halloysite nanotubes (HNTs) by hydrothermal reaction to create a novel synergistic flame retardant $(\mathrm{H}-\mathrm{U})$ of HPCP for EP. For the EP containing HPCP and $\mathrm{H}-\mathrm{U}$, the initial decomposition temperature $\left(T_{5 \%}\right)$ and the temperature of maximum decomposition rate $\left(T_{\text {max }}\right)$ increased by 11 and $17^{\circ} \mathrm{C}$ under nitrogen atmosphere compared with those of the EP containing only HPCP. Meanwhile, the EP containing HPCP and H-U exhibited better tensile and flexural properties due to the addition of rigid nanoparticles. Notably, the EP containing HPCP and $\mathrm{H}-\mathrm{U}$ reached a V-0 rating in UL-94 test and a limited oxygen index (LOI) of 35.2\%. However, with the introduction of $\mathrm{H}-\mathrm{U}$, the flame retardant performances of EP composites were weakened in the cone calorimeter test, which was probably due to the decreased height of intumescent residual char.
\end{abstract}

Keywords: epoxy resin; Hexaphenoxycyclotriphosphazene; metal-organic frame; halloysite nanotubes; flame retardancy; mechanical properties

\section{Introduction}

Epoxy resin (EP), as a crucial thermoset polymer, and is extensively used in various industries for its excellent mechanical properties, electrical insulation, adhesion strength and chemical resistances [1-5]. Nevertheless, EP is inherently flammable due to its chemical constitution, which may bring hidden danger to people's life and property. Once ignited, EP burns vigorously, and a lot of heat and smoke will be released. Thus, it is of great significance to improve its flame retardancy [6-8]. Traditionally, halogen-based flame retardants (FRs) have been widely applied for their high efficiency in improving the flame retardancy of EP. However, EP with halogen-based, especially brominated FRs, may produce poisonous smoke and toxic halogenated dibenzodioxins and dibenzofurans during combustion $[9,10]$. In consideration of environmental problems, halogen-free FRs have consequently attracted a lot of attention [11-13]. Among all halogen-free FRs, phosphoruscontaining FRs are considered as a promising candidate for EP due to their low toxicity and high efficiency [14,15].

Among different kinds of phosphorous-containing FRs, cyclotriphousphazene and its derivatives have been widely used in flame-retardant EP [16,17]. When used alone, they usually promote the formation of an intumescent char layer during combustion. However, the intumescent char layer is not compact enough, which may restrain further improvement in flame retardant performance [18]. Halloysite nanotubes ( $\left.\mathrm{HNTs}, \mathrm{Al}_{2}(\mathrm{OH})_{4} \mathrm{Si}_{2} \mathrm{O}_{5} \cdot \mathrm{nH}_{2} \mathrm{O}\right)$ are one class of common clays with a unique hollow tubular structure in nature [19]. HNT is characterized by its rich surface pore structure, high adsorption properties, large aspect ratio, and outstanding mechanical properties and thermal stability, and thus it has been widely used in drug carriers, nanocomposites, and biosensors [20-23]. Additionally, HNT 
is also applied as a flame retardant for different polymeric materials. As a rigid and thermally stable nanoadditive, HNT can not only improve the mechanical strength and modulus of the composite materials, but can also greatly enhance the thermal stability and wear resistance $[24,25]$. However, HNT is often combined with other FRs, because HNT only slows down the combustion process and cannot reduce the amount of combustible materials. Therefore, it is better to use HNT as a synergistic FR of P-containing FRs [26]. Metal-organic framework (MOF) is a porous crystalline polymer formed by coordination bonds between organic ligands and metal ions or ion clusters, which has the advantages of high porosity, large specific surface area, easy functionalization and modification [27]. MOF has made good progress in the fields of biomedicine, electrode materials, gas storage and separation, showing great application potential [28-31]. Meanwhile, MOF has also been used as a flame retardant for different polymeric materials. For example, Sai et al. reported that the porous structure of MOF can delay the time to ignition while the flame retardant efficiency improve due to the charring or crosslinking reaction catalyzed by metal element [32]. Hou et al. reported that the combination of the adsorption and catalytic effect of P-MOF enhanced the fire safety of EP [33]. Zhang et al. modified $\mathrm{MOF}\left(\mathrm{UiO} 66-\mathrm{NH}_{2}\right)$ with phytic acid, which led to the reinforced char with a strong barrier and a higher polyaromatic structure for EP samples [34].

In this paper, we developed a novel flame-retardant nanomaterial $(\mathrm{H}-\mathrm{U})$ by combining HNT with UiO66- $\mathrm{NH}_{2}$, which was used as a synergistic flame retardant for hexaphenoxycyclotriphosphazene (HPCP) in epoxy resin. The effects of H-U and HPCP on the thermal stability, mechanical properties and flame retardancy of EP were studied in detail. Additionally, the flame retardant mechanism was studied by different tests.

\section{Materials and Methods}

\subsection{Materials}

Diglycidyl ether of bisphenol A (DGEBA) with an epoxy value of $0.53 \mathrm{~mol} / 100 \mathrm{~g}$ was provided by Yueyang Baling Huaxing Petrochemical Co., Ltd. (Hunan, China). Halloysite was purchased from Runwo Materials Technology Co., Ltd. (Guangzhou, China). 2-Aminoterephthalic Acid (BDC, 95\%) and zirconium (IV) tetrachloride $\left(\mathrm{ZrCl}_{4}, 98 \%\right)$ were purchased from Sigma-Aldrich (St. Louis, MO, USA). Trichloromethane $\left(\mathrm{CHCl}_{3}\right)$, toluene, methanol, ethanol and $N, N$-dimethylformamide (DMF) were provided by Sinopharm Chemical Reagent. Co. Ltd. (Shanghai, China). 3-Aminopropyltriethoxy silane (APTES) and trimethylamine (TEA) were purchased from Sigma-Aldrich (St. Louis, MO, USA). Hexaphenoxycyclotriphosphazene (HPCP, 98\%) was purchased from Macklin Biochemical Co., Ltd. (Shanghai, China).

\subsection{Preparation of HNTs-UiO66 $(\mathrm{H}-\mathrm{U})$}

There are plentiful active groups on the surface of HNTs, and thus different kinds of functional groups can be introduced. In this work, the carboxyl functionalized HNTs (HNTs-COOH) were synthesized based on previous research [35]. Firstly, in a $500 \mathrm{~mL}$ single-necked flask, $10 \mathrm{~g}$ HNTs were uniformly dispersed in $250 \mathrm{~mL}$ of toluene through ultrasonic dispersion and magnetic stirring. Then, $10 \mathrm{~mL}$ of TEA and $20 \mathrm{~mL}$ of APTES were added to the flask, and the mixture was stirred for $24 \mathrm{~h}$ at $80^{\circ} \mathrm{C}$ under nitrogen atmosphere. The APTES-modified HNTs $\left(\mathrm{HNTs}-\mathrm{NH}_{2}\right)$ were centrifuged and washed with deionized water and ethanol. In addition, then, $\mathrm{HNTs}-\mathrm{NH}_{2}$ was placed in a vacuum oven at $50{ }^{\circ} \mathrm{C}$ for $24 \mathrm{~h}$. After that, $5 \mathrm{~g} \mathrm{HNTs}-\mathrm{NH}_{2}$ powder and $2 \mathrm{~g}$ succinic anhydride were added into $200 \mathrm{~mL}$ $\mathrm{DMF}$, and the mixture was stirred at $25^{\circ} \mathrm{C}$ for $24 \mathrm{~h}$. Similarly, the obtained HNTs-COOH was washed with deionized water and ethanol, and the washed product was dried at $50{ }^{\circ} \mathrm{C}$ under vacuum for $24 \mathrm{~h}$. Afterwards, based on our previous work [36], $3.50 \mathrm{~g} \mathrm{ZrCl}_{4}$ and $2.49 \mathrm{~g} \mathrm{BDC}-\mathrm{NH}_{2}$ were dissolved in $210 \mathrm{~mL} \mathrm{DMF}$ with magnetic stirring for $30 \mathrm{~min}$, and then $1 \mathrm{~g}$ HNTs-COOH was added into mixture with continuous stirring for $15 \mathrm{~min}$. The obtained mixture was transferred to a high-pressure autoclave, and placed at $120{ }^{\circ} \mathrm{C}$ in an oven for $24 \mathrm{~h}$. The obtained product was centrifuged, and washed with $\mathrm{DMF}, \mathrm{CHCl}_{3}$ 
and methanol for several times, and finally dried at $120^{\circ} \mathrm{C}$ under vacuum for $24 \mathrm{~h}$. The synthetic route of $\mathrm{H}-\mathrm{U}$ is shown in Figure 1.

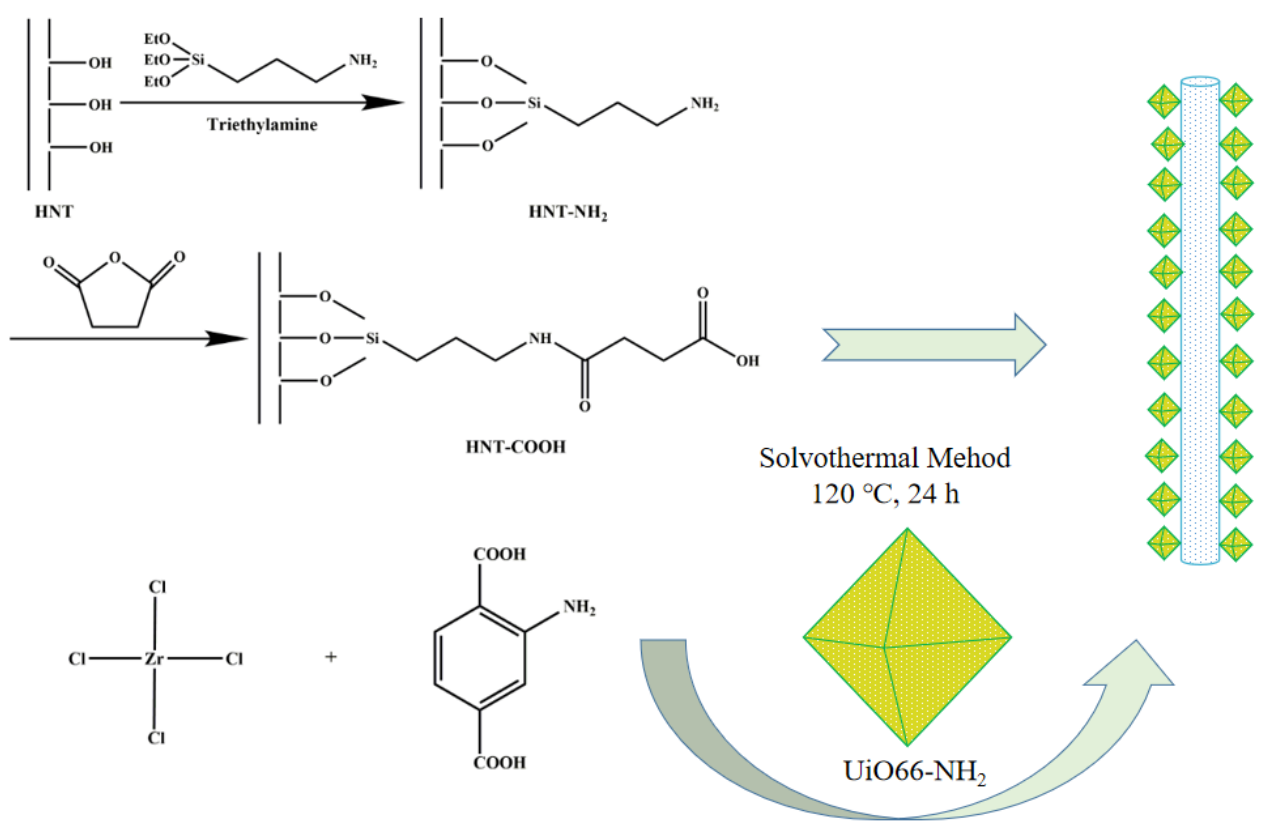

Figure 1. The synthesis of H-U.

\subsection{Fabrication of EP Thermosets}

The fabrication process of EP thermosets was as follows. A certain amount of HPCP and $\mathrm{H}-\mathrm{U}$ were added to a $250 \mathrm{~mL}$ three-necked flask, and then $30 \mathrm{~mL}$ acetone was added, followed by ultrasonically dispersing for $15 \mathrm{~min}$. A certain amount of epoxy resin was added to the flask and then the mixture was mechanically stirred at $120^{\circ} \mathrm{C}$ for $2 \mathrm{~h}$. After that, 4, 4'-diaminodiphenylsulfone (DDS) was added to the mixture, and stirred for $15 \mathrm{~min}$. The obtained mixture was heated to $130{ }^{\circ} \mathrm{C}$ and defoamed under vacuum for $5 \mathrm{~min}$. After the bubbles were removed, the mixture was poured into a mold that was preheated at $130{ }^{\circ} \mathrm{C}$ in an oven. The mixture was cured at $130{ }^{\circ} \mathrm{C}$ for $2 \mathrm{~h}, 180^{\circ} \mathrm{C}$ for $5 \mathrm{~h}$ and $200{ }^{\circ} \mathrm{C}$ for $2 \mathrm{~h}$, respectively. Finally, EP thermosets were obtained after naturally cooled to room temperature. The formulas of epoxy thermosets are listed in Table 1.

Table 1. Formulas of EP and its composites.

\begin{tabular}{ccccc}
\hline Sample ID & EP/wt $\%$ & DDS/wt $\%$ & H-U/wt $\%$ & HPCP/wt $/ \mathbf{~}$ \\
\hline EP/DDS & 75.2 & 24.8 & - & - \\
EP/DDS/HPCP-9 & 68.4 & 22.6 & - & 9.0 \\
EP/DDS/HPCP-8/H-U-1 & 68.4 & 22.6 & 1.0 & 8.0 \\
EP/DDS/HPCP-7/H-U-2 & 68.4 & 22.6 & 2.0 & 7.0 \\
EP/DDS/HPCP-6/H-U-3 & 68.4 & 22.6 & 3.0 & 6.0 \\
\hline
\end{tabular}

\subsection{Characterization and Measurements}

The Fourier transform infrared spectra were obtained using a Vector-22 FTIR spectrophotometer (IR, Bruker, Karlsruhe, Germany). Thermal gravimetric analysis (TGA) was carried out in $\mathrm{N}_{2}$ and air conditions at a heating rate of $20^{\circ} \mathrm{C} / \mathrm{min}$ from 30 to $800{ }^{\circ} \mathrm{C}$ using a TGA analyzer (209 F1, Netzsch, selb, Germany). Differential scanning calorimetry (DSC) was performed on a PerkinElmer DSC 4000 (PerkinElmer, Waltham, MA, USA) at a heating rate of $10{ }^{\circ} \mathrm{C} / \mathrm{min}$ under nitrogen. Dynamic mechanical analysis (DMA) was carried out on a DMA Q800 apparatus (TA Instruments, New Castle, DE, USA) under single cantilever bending mode at a heat-up rate of $3.0{ }^{\circ} \mathrm{C} / \mathrm{min}$ from 30 to $250{ }^{\circ} \mathrm{C}$. Mechanical properties were evaluated by a CMT6104 universal testing machine (MTS Systems 
Co., Ltd., Nanjing, China). The tensile test was conducted based on ASTM D638 by using the dumbbell-shaped samples. Three-point flexural measurements were undertaken in accordance with ASTM D790. Five specimens for each sample were used, and the average values were reported. Limiting oxide index (LOI) was recorded on a LOI tester (HC-2, Jiangning Analyzer Instrument, Nanjing, China) according to GB2406-80, and the dimension of samples was $130 \mathrm{~mm} \times 6.5 \mathrm{~mm} \times 3 \mathrm{~mm}$. UL-94 vertical burning tests were conducted using a vertical burning instrument (CZF-3, Jiangning Analyzer Instrument, Nanjing, China) with specimen dimensions of $130 \mathrm{~mm} \times 13 \mathrm{~mm} \times 3 \mathrm{~mm}$ according to ASTM D3801. Cone calorimeter tests were performed on a cone calorimeter (CONE, Fire Testing Technology, East Grinstead, UK) according to ISO-5660. Square specimens $(100 \mathrm{~mm} \times 100 \mathrm{~mm} \times 3 \mathrm{~mm})$ were irradiated at a heat flux of $35 \mathrm{~kW} / \mathrm{m}^{2}$. Typically, three specimens were needed for each sample, and the error of the obtained data was reproducible within $\pm 5 \%$. The morphology of residual char after cone calorimeter test was observed by a scanning electron microscope (SEM, S-4800, Hitachi, Japan). A transmission electron microscope (TEM, JEOL, 1230, Akishima, Japan) was used to acquire detect the phase morphology of epoxy composites. Thermogravimetric analysis/infrared spectrometry (TGA-FTIR) was conducted using a TGA analyzer coupl ed with a Thermo Nicolet IS10 FTIR spectroscopy (TGA, 209 F1, Netzsch, selb, Germany; Nicolet IS10 FTIR, Madison, Wisconsin, USA) under $\mathrm{N}_{2}$ conditions at a heating rate of $20^{\circ} \mathrm{C} / \mathrm{min}$ from 30 to $800{ }^{\circ} \mathrm{C}$. About $6.00 \mathrm{mg}$ sample was used.

\section{Results and Discussion}

\subsection{Characterization of $\mathrm{H}-\mathrm{U}$}

TEM images of HNTs, HNTs-COOH, UiO66- $\mathrm{NH}_{2}$, and H-U, and SEM images of HNTs$\mathrm{COOH}$ and $\mathrm{H}-\mathrm{U}$ are presented at Figure 2. As shown in Figure 2a, the HNTs possessed a unique hollow tubular structure with large length-diameter ratio. When modified with $-\mathrm{COOH}$, the surface of HNTs became rough, and the diameter was larger than that of the unmodified HNTs. Unlike HNTs, the UiO-66- $\mathrm{NH}_{2}$ was an irregular sphere (see Figure $2 \mathrm{~d}$ ). For the H-U in Figure 2f, the surface of the tube was covered with a layer of irregular spheres, which illustrated that UiO66- $\mathrm{NH}_{2}$ had been successfully wrapped onto the surface of the HNTs of H-U tube.
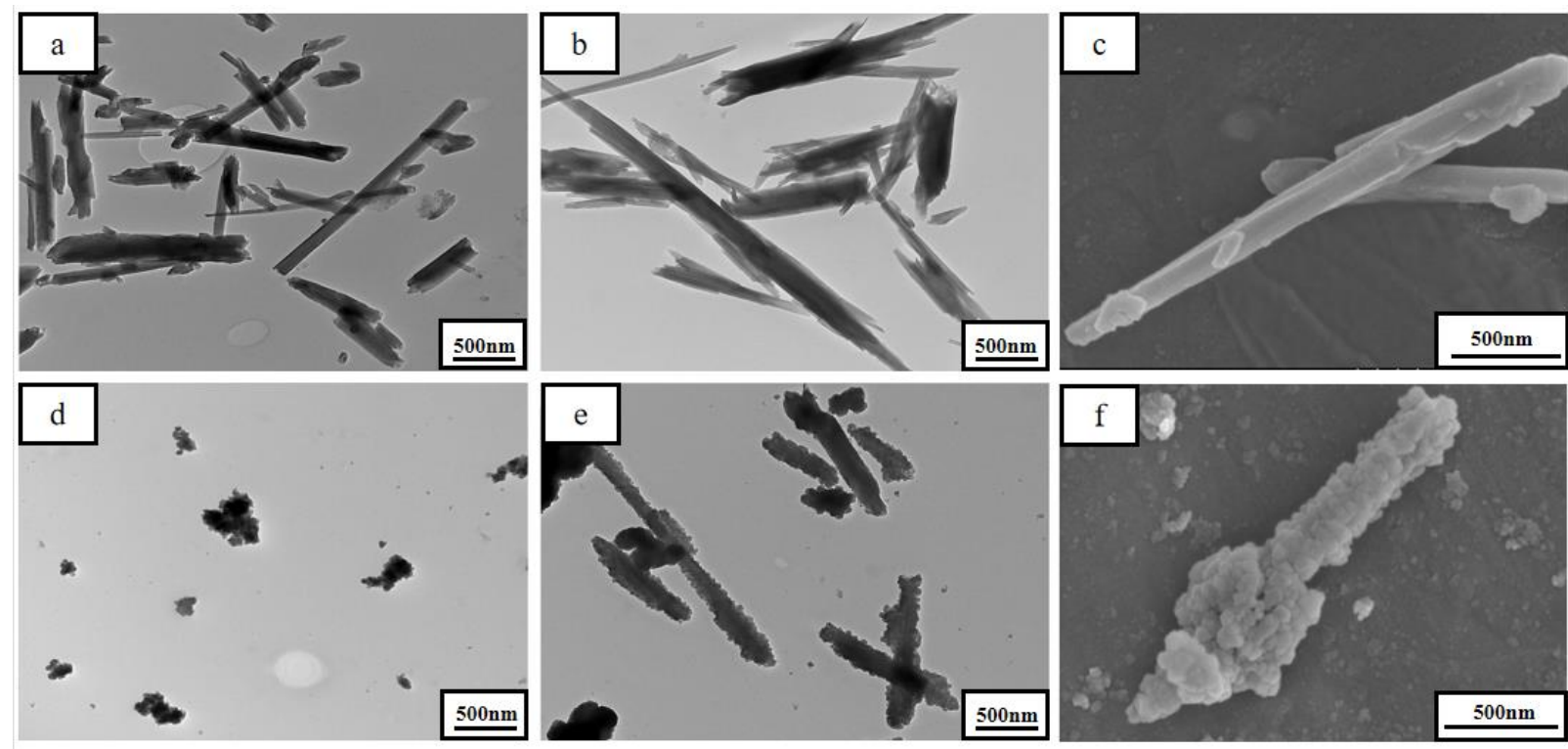

Figure 2. TEM images of HNTs (a), HNTs-COOH (b), UiO66-NH 2 (d), and H-U (e); and SEM images of HNTs-COOH (c) and $\mathrm{H}-\mathrm{U}(\mathbf{f})$. 
FT-IR technique was also employed to characterize the structure change of nanomaterials, with the spectra shown in Figure 3. The absorption peaks at 3695 and $3623 \mathrm{~cm}^{-1}$ belonged to the stretching vibration of the hydroxyl groups of HNTs. The sharp absorption peak at $913 \mathrm{~cm}^{-1}$ was attributed to the hydroxyl group attached to the aluminum. Additionally, there was an absorption peak of Si-O bond at $1033 \mathrm{~cm}^{-1}$. For $\mathrm{HNT}-\mathrm{NH}_{2}$, the stretching peaks of $-\mathrm{NH}_{2}$ groups appeared around $3451 \mathrm{~cm}^{-1}$. The carbonyl vibration peaks of HNTs-COOH could be observed at 1542 and $1646 \mathrm{~cm}^{-1}$, respectively. For UiO66$\mathrm{NH}_{2}$, the broad band between 3374 and $3470 \mathrm{~cm}^{-1}$ demonstrated the presence of the $-\mathrm{NH}_{2}$ groups. The absorption peaks around 1256 and $1435 \mathrm{~cm}^{-1}$ were assigned to the absorption peaks of C-N and N-H groups. The peaks located at 1388 and $1560 \mathrm{~cm}^{-1}$ were assigned to the asymmetric and symmetric stretching vibrations of the -COO- connected with $\mathrm{Zr}^{4+}$, respectively. Generally, H-U showed similar absorption peaks to UiO66- $-\mathrm{NH}_{2}$. However, an absorption peak of Si-O bond appeared at $1033 \mathrm{~cm}^{-1}$ in the FT-IR spectrum of H-U, further indicating that UiO66- $\mathrm{NH}_{2}$ had been successfully grafted on the surface of HNTs.

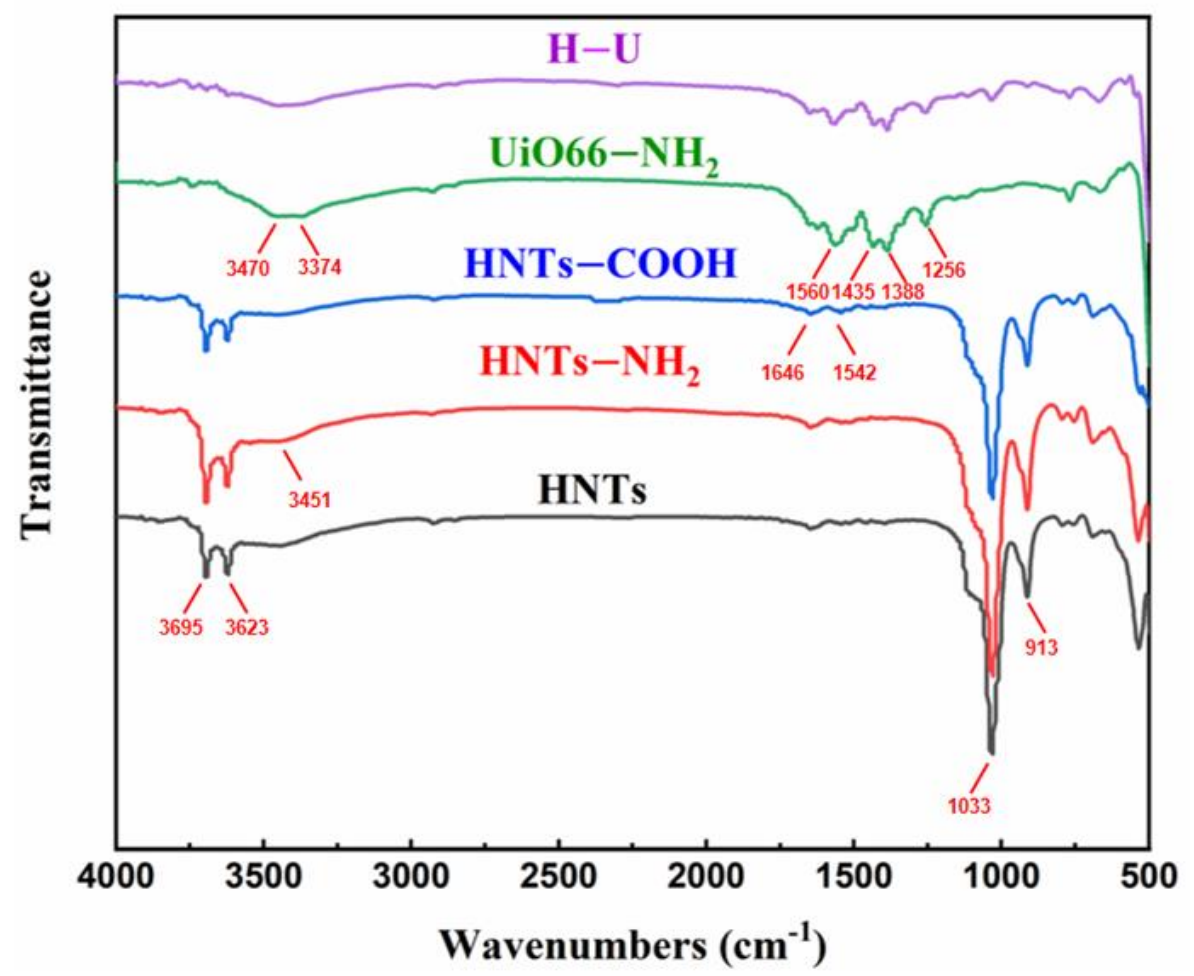

Figure 3. FT-IR spectra of HNTs, HNTs-NH $\mathrm{H}_{2}, \mathrm{HNTs}-\mathrm{COOH}, \mathrm{UiO} 66-\mathrm{NH}_{2}, \mathrm{H}-\mathrm{U}$.

\subsection{Thermal Properties}

The glass transition temperature $\left(T_{\mathrm{g}}\right)$ of the cured epoxy resin is important information for evaluating its thermal resistance, and thus DSC was applied to investigate the influence of $\mathrm{H}-\mathrm{U}$ on the $T_{\mathrm{g}}$ of EP samples. As shown in Figure 4, the $T_{\mathrm{g}}$ value of pure EP/DDS was as high as $195^{\circ} \mathrm{C}$. With the introduction of $9.0 \mathrm{wt} \% \mathrm{HPCP}$, the $T_{\mathrm{g}}$ value of EP/DDS/HPCP-9 obviously reduced to $185^{\circ} \mathrm{C}$ due to the plasticizing effect of HPCP. Notably, replacing part of HPCP with $\mathrm{H}-\mathrm{U}$ contributed to increasing the $T_{\mathrm{g}}$ values of EP/DDS/HPCP/H-U samples. For instance, the EP/DDS/HPCP-6/H-U-3 sample exhibited a $T_{\mathrm{g}}$ value of $192{ }^{\circ} \mathrm{C}$, which was very close to that of EP/DDS sample. It was supposed that the incorporation of rigid $\mathrm{H}-\mathrm{U}$ restricted the mobility of epoxy chains and thus increased the $T_{\mathrm{g}}$ value of EP samples.

Additionally, TGA test was also performed to further estimate the thermal stability of the cured epoxy resins. The TG and DTG curves of epoxy thermosets are shown in Figure 5. The initial decomposition temperature (temperature at $5 \%$ weight loss, $T_{5 \%}$ ), temperature 
of maximum decomposition rate $\left(T_{\max }\right)$, maximum decomposition rate $\left(\mathrm{R}_{\max }\right)$ and char residue at $800{ }^{\circ} \mathrm{C}(\mathrm{CY})$ are listed in Table 2.

In $\mathrm{N}_{2}$ conditions, the $T_{5 \%}$ and $T_{\max }$ values of pure EP/DDS reached $391^{\circ} \mathrm{C}$ and $433^{\circ} \mathrm{C}$, respectively. The addition of HPCP reduced the $T_{5 \%}$ and $T_{\max }$ values of EP/DDS/HPCP-9 sample due to the promoting decomposition effect of phosphorus-based compounds from HPCP $[16,37]$. With the increasing loading level of $H-U$, the $T_{5 \%}$ values of the cured epoxy resins gradually increased, indicating that the thermal stability was effectively remedied. This can be explained as follows: firstly, the increase in $T_{5 \%}$ can be primarily attributed to the decreased content of phosphorus; secondly, the interfacial reaction between HNTs and EP matrix can also retard the decomposition at initial stage [38]. At high temperature, inorganic particles can hinder the movement of polymer chain in the interface region between polymer and inorganic phase [39]. Meanwhile, the presence of thermally stable UiO66- $\mathrm{NH}_{2}$ particles can also improve the thermal resistance of EP composites [40]. For $T_{\max }$, it showed a similar trend to the initial decomposition temperature. Additionally, as shown in Table 2, the char yield of EP composite was obviously increased when $9 \mathrm{wt} \%$ HPCP was added, indicating that HPCP effectively promoted the carbon formation of epoxy matrix. After replacing $1 \mathrm{wt} \% \mathrm{HPCP}$ with $\mathrm{H}-\mathrm{U}$, the char yield increased from $20.0 \%$ to $21.5 \%$. However, the further increase in $\mathrm{H}-\mathrm{U}$ content decreased the char yield of EP thermosets, and the char yield of EP/DDS/HPCP-6/H-U-3 sample was basically consistent with that of EP/DDS/HPCP-9 sample.

In air conditions, the cured epoxy resins showed two degradation stages. The first stage was due to the degradation of principal polymer networks, while the second one was attributed to the oxidative degradation of formed char [41,42]. In the initial thermal oxidation degradation stage, the presence of $\mathrm{H}-\mathrm{U}$ promoted the thermal oxidative stability of EP/DDS/HPCP composite. At elevated temperature, $\mathrm{H}-\mathrm{U}$ also increased the char yield of EP/DDS/HPCP/H-U composites.

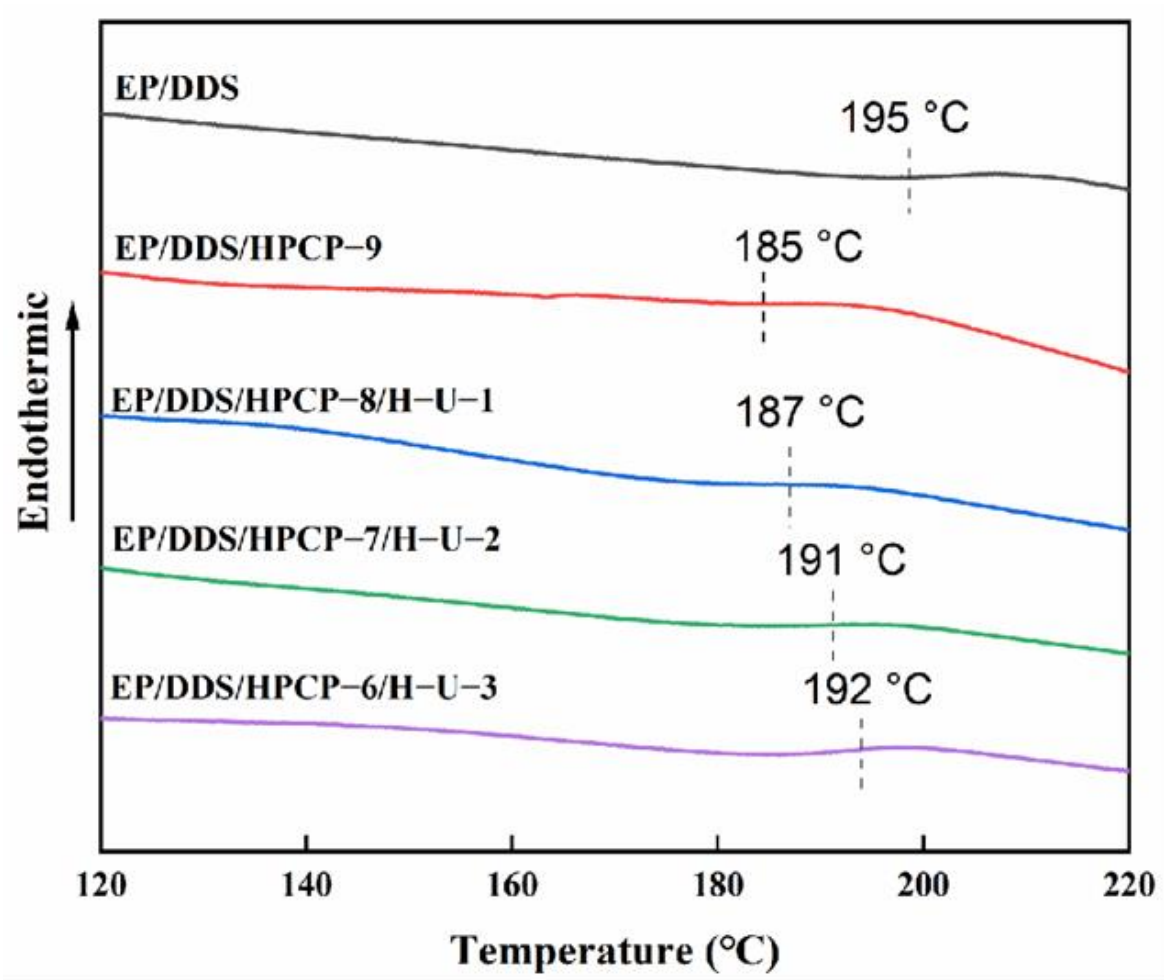

Figure 4. $\mathrm{T}_{\mathrm{g}} \mathrm{s}$ of EP and its composites obtained by DSC. 

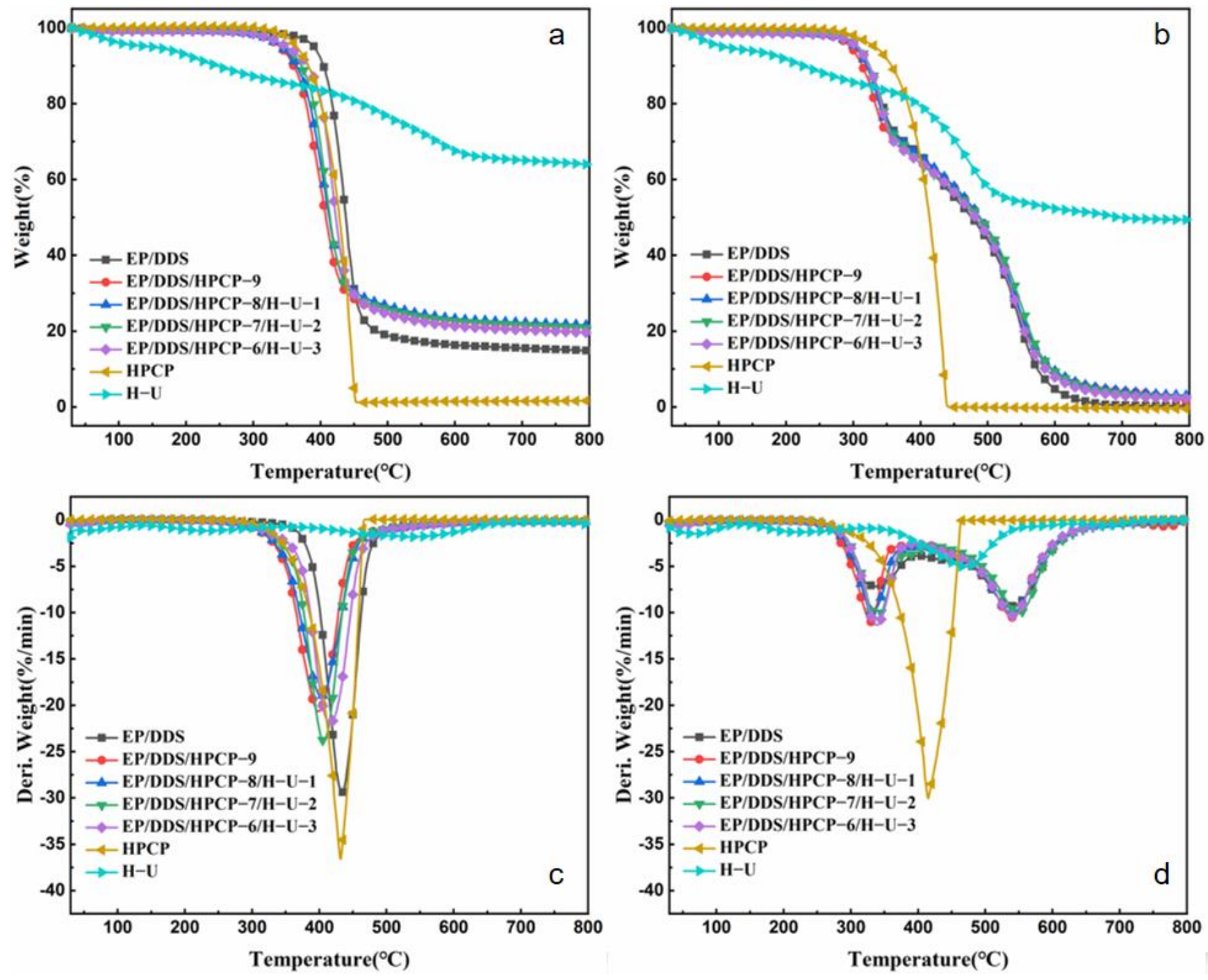

Figure 5. TG and DTG plots of EP samples, H-U and HPCP in $\mathrm{N}_{2}(\mathbf{a}, \mathbf{c})$ and air $(\mathbf{b}, \mathbf{d})$ conditions.

Table 2. TGA results of EP and its composites.

\begin{tabular}{|c|c|c|c|c|c|c|c|}
\hline Atmosphere. & Sample & $\begin{array}{l}T_{5 \%} \% \\
\left({ }^{\circ} \mathrm{C}\right)\end{array}$ & $\begin{array}{c}T_{\max 1} \\
\left({ }^{\circ} \mathrm{C}\right)\end{array}$ & $\begin{array}{c}R_{\max 1} \\
(\% / \mathrm{min})\end{array}$ & $\begin{array}{c}T_{\max 1} \\
\left({ }^{\circ} \mathrm{C}\right)\end{array}$ & $\begin{array}{c}R_{\max 2} \\
(\% / \mathrm{min})\end{array}$ & $\begin{array}{l}\text { CY } \\
(\%)\end{array}$ \\
\hline \multirow{7}{*}{$\mathrm{N}_{2}$} & EP/DDS & 391 & 433 & 29.5 & - & - & 14.8 \\
\hline & $\mathrm{EP} / \mathrm{DDS} / \mathrm{HPCP}-9$ & 339 & 399 & 20.7 & - & - & 20.0 \\
\hline & $\mathrm{EP} / \mathrm{DDS} / \mathrm{HPCP}-8 / \mathrm{H}-\mathrm{U}-1$ & 341 & 403 & 19.0 & - & - & 21.5 \\
\hline & EP/DDS/HPCP-7/H-U-2 & 348 & 406 & 23.8 & - & - & 20.8 \\
\hline & $\mathrm{EP} / \mathrm{DDS} / \mathrm{HPCP}-6 / \mathrm{H}-\mathrm{U}-3$ & 350 & 416 & 21.9 & - & - & 19.6 \\
\hline & $\mathrm{HPCP}$ & 362 & 431 & 36.6 & - & - & 1.6 \\
\hline & $\mathrm{H}-\mathrm{U}$ & 147 & 538 & 1.8 & - & - & 63.9 \\
\hline \multirow{7}{*}{ Air } & EP/DDS & 306 & 338 & 7.2 & 537 & 9.3 & 0.3 \\
\hline & EP/DDS/HPCP-9 & 295 & 330 & 11.0 & 540 & 10.5 & 1.8 \\
\hline & EP/DDS/HPCP-8/H-U-1 & 302 & 332 & 9.9 & 539 & 10.0 & 3.0 \\
\hline & EP/DDS/HPCP-7/H-U-2 & 308 & 338 & 10.6 & 550 & 10.1 & 2.3 \\
\hline & $\mathrm{EP} / \mathrm{DDS} / \mathrm{HPCP}-6 / \mathrm{H}-\mathrm{U}-3$ & 306 & 339 & 11.3 & 542 & 10.3 & 2.3 \\
\hline & $\mathrm{HPCP}$ & 332 & 415 & 30.1 & - & - & 0 \\
\hline & $\mathrm{H}-\mathrm{U}$ & 106 & 468 & 5.1 & - & - & 49.4 \\
\hline
\end{tabular}




\subsection{Mechanical Properties}

The DMA test was conducted to study the dynamic mechanical properties of the cured epoxy resins, and the curves of storage modulus $\left(E^{\prime}\right)$ and $\tan$ delta (Tan $\delta$ ) versus temperature are shown in Figure 6. Storage modulus is an important parameter to evaluate the rigidity of materials. As shown in Figure 6, the $E^{\prime}$ of epoxy thermoset at $30^{\circ} \mathrm{C}$ was significantly reduced after the addition of HPCP. With the addition of $\mathrm{H}-\mathrm{U}$, the $E^{\prime}$ at $30^{\circ} \mathrm{C}$ was increased. For instance, the $E^{\prime}$ of EP/DDS/HPCP-6/H-U-3 sample reached $2652 \mathrm{MPa}$, which was little higher than that of pure EP/DDS sample. It was inferred that HNTs, as a rigid nanotube, increased the rigidity of EP thermoset through the interface reaction between HNTs and matrix [39]. Meanwhile, the amine groups on the surface of $\mathrm{H}-\mathrm{U}$ might also react with the epoxide groups during curing process, thus promoting the interfacial strength [34]. In addition, the temperature corresponding to the peak value of the tan delta curve is the glass transition temperature $\left(T_{\mathrm{g}}\right)$. Similar to $E^{\prime}$, the $T_{\mathrm{g}}$ value of EP/DDS/HPCP9 sample was lower than that of EP/DDS sample. With the addition of $\mathrm{H}-\mathrm{U}$, the $T_{\mathrm{g}}$ was almost unchanged, which may be assigned to two competitive factors: the rigid-phase reinforcement and destroying of the epoxy network structure [43-45].

Additionally, the tensile and flexural properties of EP thermosets were also tested to further study the effect of $\mathrm{H}-\mathrm{U}$ on mechanical properties of the cured epoxy resins, and the data is shown in Table 3. Apparently, the tensile and flexural strengths of EP thermosets were reduced when adding $9 \mathrm{wt} \% \mathrm{HPCP}$, indicating the negative effect of HPCP on the mechanical properties of EP thermosets. However, when a part of HPCP was replaced by $\mathrm{H}-\mathrm{U}$, the mechanical properties were improved. Especially for EP/DDS/HPCP-7/HU-2 sample, the tensile and flexural strengths were $68.75 \mathrm{MPa}$ and $108.01 \mathrm{MPa}$, which were fairly close to those of EP/DDS sample. On the other hand, the elastic and flexural moduli were continuously increased with the increasing content of $\mathrm{H}-\mathrm{U}$. In this study, UiO66- $\mathrm{NH}_{2}$ was covalently bonded with HNTs to improve the compatibility between EP and nanoparticles [46]. As shown in Figure 7, H-U was uniformly dispersed in the epoxy matrix. As a result, EP/DDS/HPCP/H-U samples exhibited better mechanical properties in comparison with EP/DDS/HPCP-9 sample, indicating that $\mathrm{H}-\mathrm{U}$, as a synergist of HPCP, owned its practical significance.

Table 3. Mechanical properties of EP thermosets.

\begin{tabular}{|c|c|c|c|c|c|c|}
\hline Sample & $\begin{array}{c}\text { Tensile Strength } \\
\text { (MPa) }\end{array}$ & $\begin{array}{l}\text { Elastic Modulus } \\
(\mathrm{MPa})\end{array}$ & $\begin{array}{l}\text { Flexural Strength } \\
\qquad(\mathrm{MPa})\end{array}$ & $\begin{array}{l}\text { Flexural Modulus } \\
\text { (MPa) }\end{array}$ & $\begin{array}{c}E^{\prime} \\
(\mathbf{M P a})\end{array}$ & $\begin{array}{c}T_{g} \\
\left({ }^{\circ} \mathrm{C}\right)\end{array}$ \\
\hline $\mathrm{EP} / \mathrm{DDS}$ & $71.2 \pm 5.3$ & $213 \pm 100$ & $109.0 \pm 1.9$ & $2932 \pm 104$ & 2642 & 225 \\
\hline $\mathrm{EP} / \mathrm{DDS} / \mathrm{HPCP}-9$ & $58.6 \pm 8.4$ & $213 \pm 71$ & $91.5 \pm 4.6$ & $3124 \pm 143$ & 2352 & 206 \\
\hline $\mathrm{EP} / \mathrm{DDS} / \mathrm{HPCP}-8 / \mathrm{H}-\mathrm{U}-1$ & $62.4 \pm 2.4$ & $281 \pm 128$ & $107.5 \pm 2.8$ & $3164 \pm 107$ & 2450 & 204 \\
\hline $\mathrm{EP} / \mathrm{DDS} / \mathrm{HPCP}-7 / \mathrm{H}-\mathrm{U}-2$ & $68.8 \pm 7.5$ & $343 \pm 120$ & $108.0 \pm 5.0$ & $2779 \pm 120$ & 2525 & 205 \\
\hline $\mathrm{EP} / \mathrm{DDS} / \mathrm{HPCP}-6 / \mathrm{H}-\mathrm{U}-3$ & $60.2 \pm 2.1$ & $514 \pm 101$ & $111.1 \pm 6.6$ & $3124 \pm 115$ & 2652 & 204 \\
\hline
\end{tabular}

\subsection{Flame Retardant Performance}

To study the synergistic flame retardant effect of HPCP and H-U, limiting oxygen index (LOI), UL-94 vertical burning and cone calorimeter tests were conducted. The corresponding data are presented in Table 4 . Pure EP burned vigorously in air, and it suffered a low LOI value of $24.5 \%$ and could not pass any rating in the UL-94 vertical burning test. For the EP/DDS/HPCP-9 sample, it could not self-extinguish after the flame was removed in the UL-94 test, and thus its UL-94 rating was only NR. However, the LOI value of EP/DDS/HPCP-9 increased to $28.4 \%$. This phenomenon can be assigned to the intumescent char layer immediately formed after ignition, which can suppress the combustion to some extent, but the layer was not dense enough to inhibit further combustion. With the increasing content of $\mathrm{H}-\mathrm{U}$, the LOI values and UL-94 ratings were significantly improved despite the decreasing content of HPCP. For EP/DDS/HPCP-6/HU-3, its LOI reached up to $35.2 \%$, UL-94 rating increased to V-0, and it showed good self-extinguishing performance, indicating the flame retardant effect of H-U. Digital images 
of EP/DDS/HPCP-9 and EP/DDS/HPCP-6/H-U-3 samples after UL-94 tests are shown in Figure 8. After the addition of $\mathrm{H}-\mathrm{U}$, the thermal resistance of EP nanocomposites was improved (as described in Section 3.2), and thus the nanocomposites were easier to selfextinguish after being ignited. Meanwhile, the denser residual char was formed with the introduction of $\mathrm{H}-\mathrm{U}$, which prevented the transfer of heat and mass. This may be the reason that EP/DDS/HPCP/H-U samples performed better than EP/DDS/HPCP-9 sample in LOI and UL-94 tests.
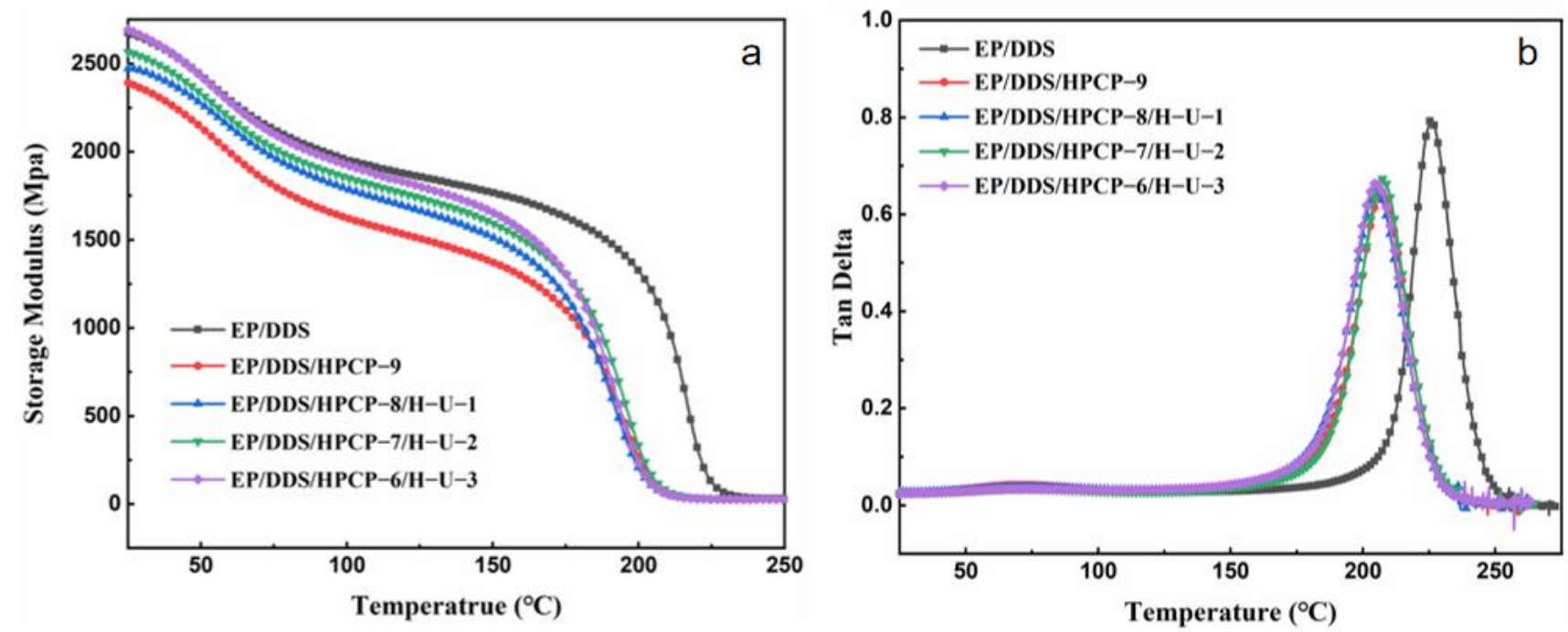

Figure 6. Storage modulus (a) and tan delta (b) curves of EP samples vs. temperature.

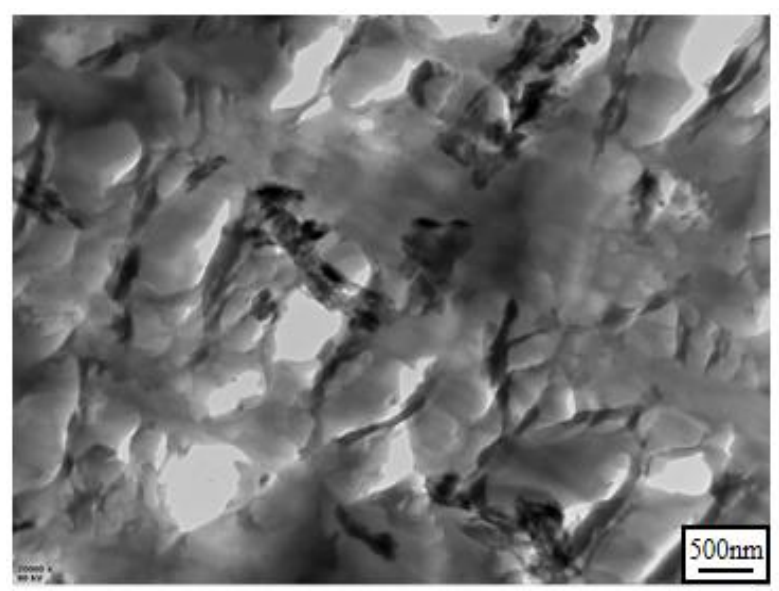

Figure 7. TEM image of the fracture surfaces of EP/DDS/HPCP-6/H-U-3.

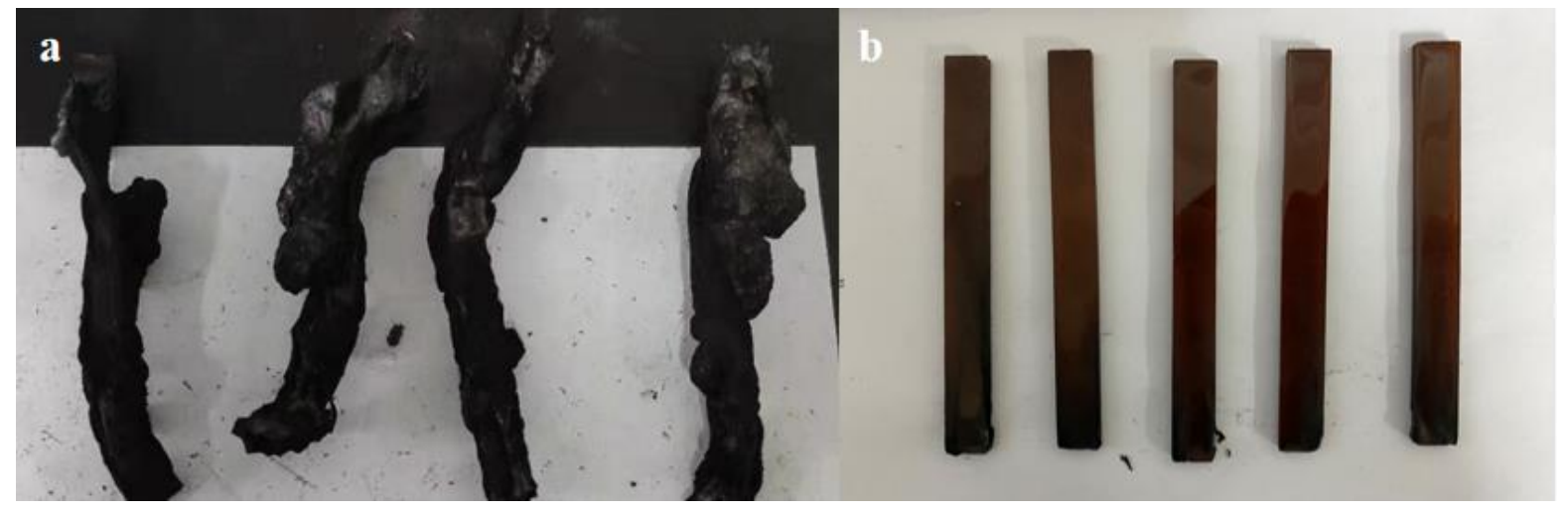

Figure 8. Digital images of EP/DDS/HPCP-9 (a) and EP/DDS/HPCP-6/H-U-3 (b) samples after UL-94 tests. 
Additionally, a cone calorimeter test was also performed to assess the flammability of polymers. The experimental results are listed in Figure 9 and Table 4. Similar to TG results, the TTI of EP/DDS/HPCP-9 sample was reduced due to the catalytic effect of phosphorus-based compounds. With the addition of $\mathrm{H}-\mathrm{U}$, the TTIs of EP/DDS/HPCP/H$\mathrm{U}$ samples increased. In addition, incorporating HPCP reduced the $\mathrm{pHRR}$ and THR from $942 \mathrm{~kW} / \mathrm{m}^{2}$ and $84.4 \mathrm{MJ} / \mathrm{m}^{2}$ of EP/DDS sample to $481 \mathrm{~kW} / \mathrm{m}^{2}$ and $41.7 \mathrm{MJ} / \mathrm{m}^{2}$, respectively. Such notable reductions may be due to the protection effect of intumescent char layer formed by HPCP under long-term thermal radiation. However, with the addition of $\mathrm{H}-\mathrm{U}$, the height of the char layer decreased significantly, as shown in Figure 10. The decrease in the height of the intumescent char layer resulted in the weakening of heat insulation and smoke suppression. Hence, the pHRR and THR of EP/DDS/HPCP/H-U samples increased to some extent. The phosphorus-based fragments produced by HPCP can promote the formation of stable intumescent char layer on the surface of epoxy matrix. Under the circumstance of constant heat, such stable intumescent layer can reduce the radiation of heat to the matrix, suppress the decomposition of the matrix and the release of flammable gases. As a result, the heat release was reduced during the combustion process. However, the thickness of the layer decreased with the introduction of $\mathrm{H}-\mathrm{U}$. Hence, the flame retardant effect of the char in the condensed phase was weakened. Likewise, the SPR and TSR values were also increased due to the decreased thickness of char layer. In sum, the introduction of $\mathrm{H}-\mathrm{U}$ can enhance the performances of EP/DDS/HPCP sample in LOI and UL-94 tests due to its promotion effect in improving the char density, but under constant heat radiation, introducing $\mathrm{H}-\mathrm{U}$ reduced the height of char, which weakened the flame retardancy and smoke suppression of EP samples.

Table 4. Combustion data of EP samples.

\begin{tabular}{|c|c|c|c|c|c|c|c|}
\hline \multirow{2}{*}{ Sample } & \multirow{2}{*}{$\begin{array}{l}\text { LOI } \\
(\%)\end{array}$} & \multicolumn{3}{|c|}{ UL-94 } & \multirow{2}{*}{$\begin{array}{c}\text { TTI } \\
\text { (s) }\end{array}$} & \multirow{2}{*}{$\begin{array}{c}\text { pHRR } \\
\left(\mathbf{k W} / \mathrm{m}^{2}\right)\end{array}$} & \multirow{2}{*}{$\begin{array}{c}\text { THR } \\
\left(\mathrm{MJ} / \mathrm{m}^{2}\right)\end{array}$} \\
\hline & & $t_{1}(s)$ & $t_{2}(s)$ & Rating & & & \\
\hline $\mathrm{EP} / \mathrm{DDS}$ & 24.5 & 80 & - & NR & 100 & 942 & 84.4 \\
\hline $\mathrm{EP} / \mathrm{DDS} / \mathrm{HPCP}-9$ & 28.4 & - & - & NR & 80 & 481 & 40.7 \\
\hline $\mathrm{EP} / \mathrm{DDS} / \mathrm{HPCP}-8 / \mathrm{H}-\mathrm{U}-1$ & 31.6 & 7 & 12 & $\mathrm{~V}-1$ & 82 & 604 & 44.2 \\
\hline $\mathrm{EP} / \mathrm{DDS} / \mathrm{HPCP}-7 / \mathrm{H}-\mathrm{U}-2$ & 33.7 & 11 & 8 & $\mathrm{~V}-1$ & 81 & 586 & 64.9 \\
\hline $\mathrm{EP} / \mathrm{DDS} / \mathrm{HPCP}-6 / \mathrm{H}-\mathrm{U}-3$ & 35.2 & 3 & 3 & $\mathrm{~V}-0$ & 92 & 658 & 51.3 \\
\hline
\end{tabular}
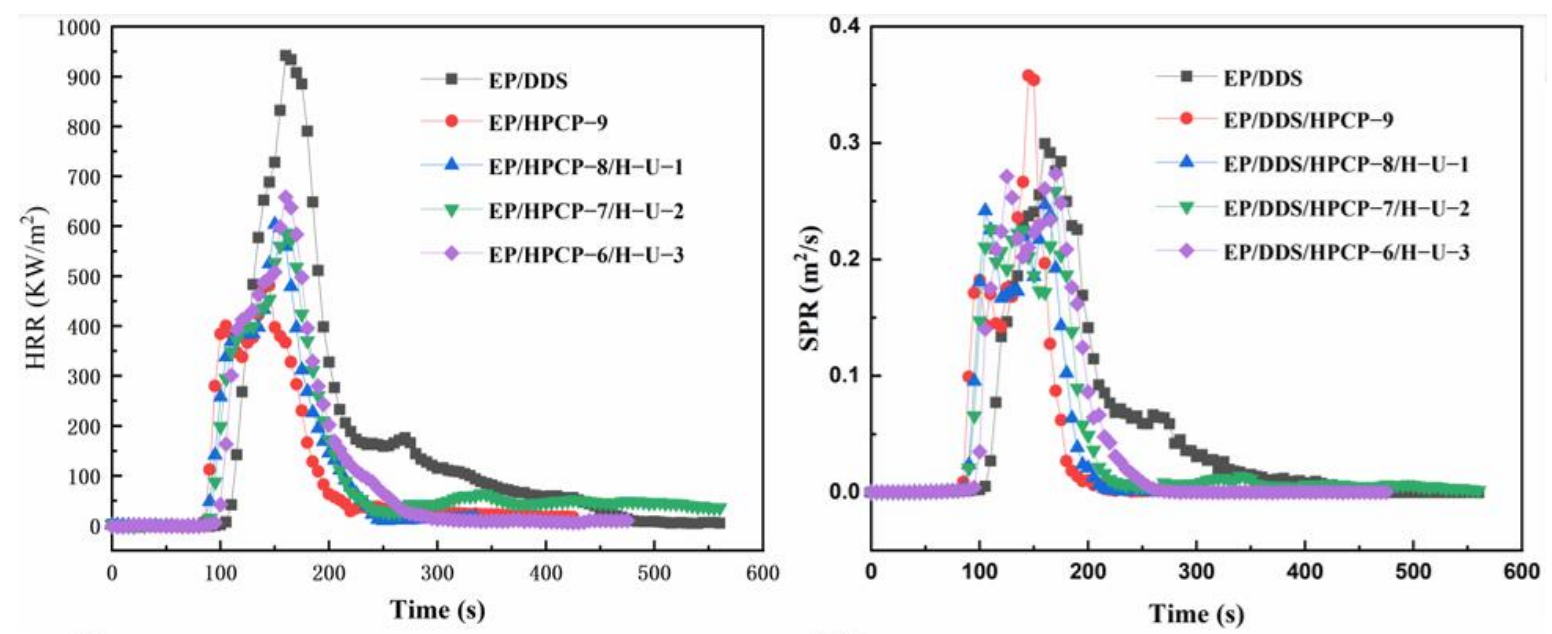

Figure 9. Cont. 

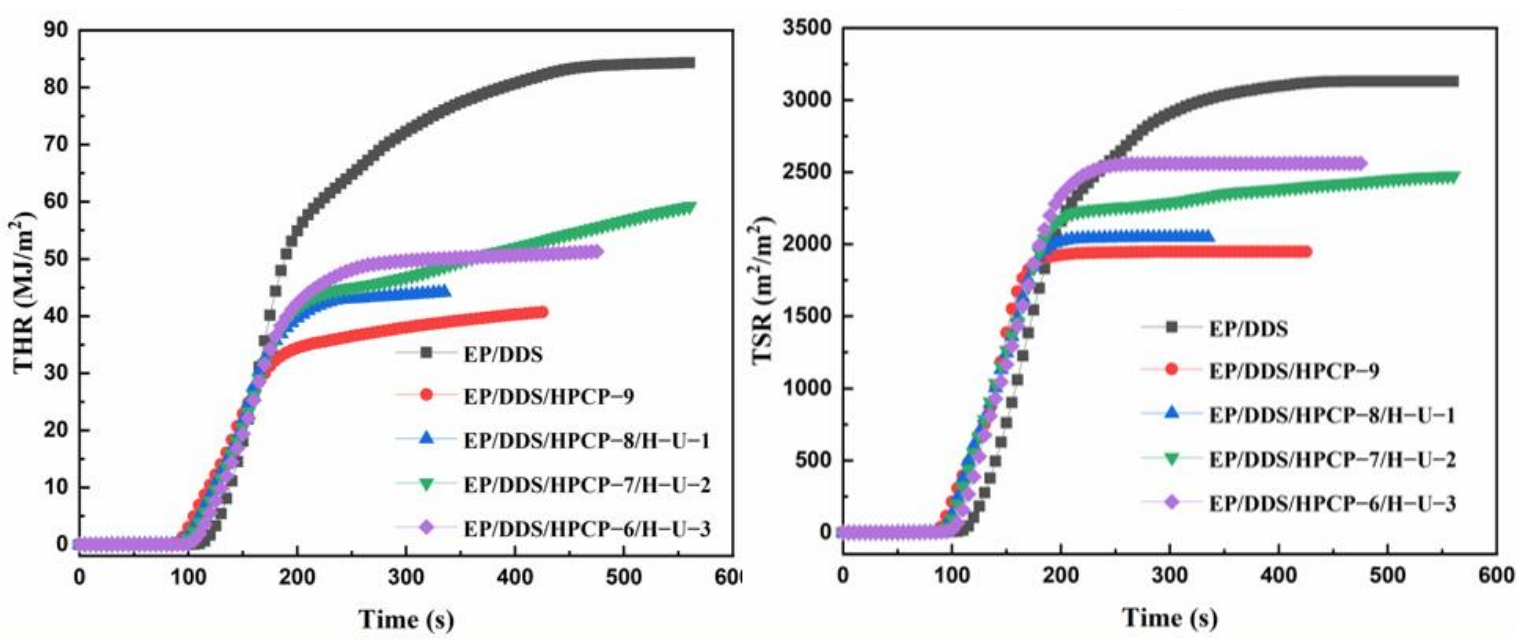

Figure 9. Plots of HRR (a), THR (b), SPR (c), and TSR (d) versus time of EP and its composites.

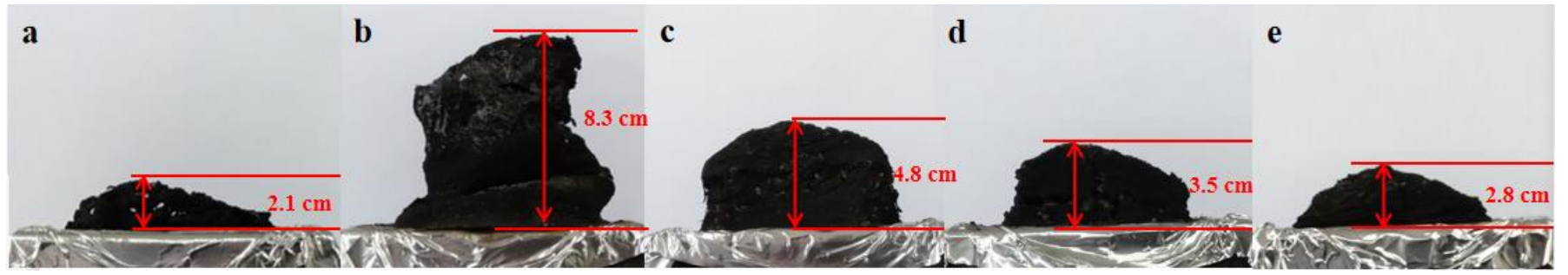

Figure 10. Digital photos of char layers of EP/DDS (a), EP/DDS/HPCP-9 (b), EP/DDS/HPCP-8/H-U-1 (c), EP/DDS/HPCP7/H-U-2 (d), and EP/DDS/HPCP-6/H-U-3 (e) after cone tests.

\subsection{Flame Retardant Mechanism}

TG-IR under $\mathrm{N}_{2}$ conditions was conducted to detect the evolution of volatilized products for EP samples during thermal degradation. The TG-IR spectra of gas products of EP thermosets are shown in Figures 11 and 12. As presented in Figures 11 and 12, both EP/DDS/HPCP-9 and EP/DDS/HPCP-6/H-U-3 showed similar characteristic peaks at $3720-3860 \mathrm{~cm}^{-1}$ (O-H), 2020-2230 $\mathrm{cm}^{-1}$ (carbon monoxide), $1730 \mathrm{~cm}^{-1}$ (C-O), $1530 \mathrm{~cm}^{-1}$ (benzene), and $1160 \mathrm{~cm}^{-1}$ (aliphatic compounds). Figure 12a showed total absorbance of decomposition products of EP composites. Obviously, the total absorbance of decomposition products of EP/DDS reached a maximum while that of EP/DDS/HPCP-9 was on the lowest level. Additionally, the absorbance of aliphatic compounds at $1160 \mathrm{~cm}^{-1}$ and hydrocarbons at $2970 \mathrm{~cm}^{-1}$ of EP/DDS/HPCP-6/H-U-3 were higher than that of EP/DDS/HPCP-9. This phenomenon indicates that the introduction of $\mathrm{H}-\mathrm{U}$ leads to a worse carbon promotion effect, which matches the previous test results.

The morphology and chemical composition of the char residues after cone calorimeter tests were analyzed to study the flame retardant effect in condensed phase by SEM. As presented in Figure 13a, the char residue of pure EP/DDS was loose, with lots of pore spaces, indicating that pure EP thermosets cannot form continuous and stable char during combustion. In terms of EP/DDS/HPCP-9, the char residue was much denser due to the introduction of P-containing flame retardant, which is conducive to heat and oxygen isolation and combustible gas suppression. Noticeably, for EP/DDS/HPCP-6/H-U-3, the char residue was compact and continuous. These results indicate that $\mathrm{H}-\mathrm{U}$ can effectively promote the carbon formation of epoxy resin during combustion, thus endowing the epoxy resin with good flame retardancy. The EDS spectra showed that the carbon was the major component of char residues. In addition, a lot of $P$ elements appeared in the char residue of EP/DDS/HPCP-9, indicating that the catalytic charring effect of P-containing groups in the condensed phase. For EP/DDS/HPCP-6/H-U-3, the char residues contained $\mathrm{Zr}$ 
(4.69\%) and $\mathrm{Al}(1.11 \%)$ elements, which suggested that the presence of $\mathrm{Al}$ and $\mathrm{Zr}$ might be responsible for catalyzing the formation of denser char layers.
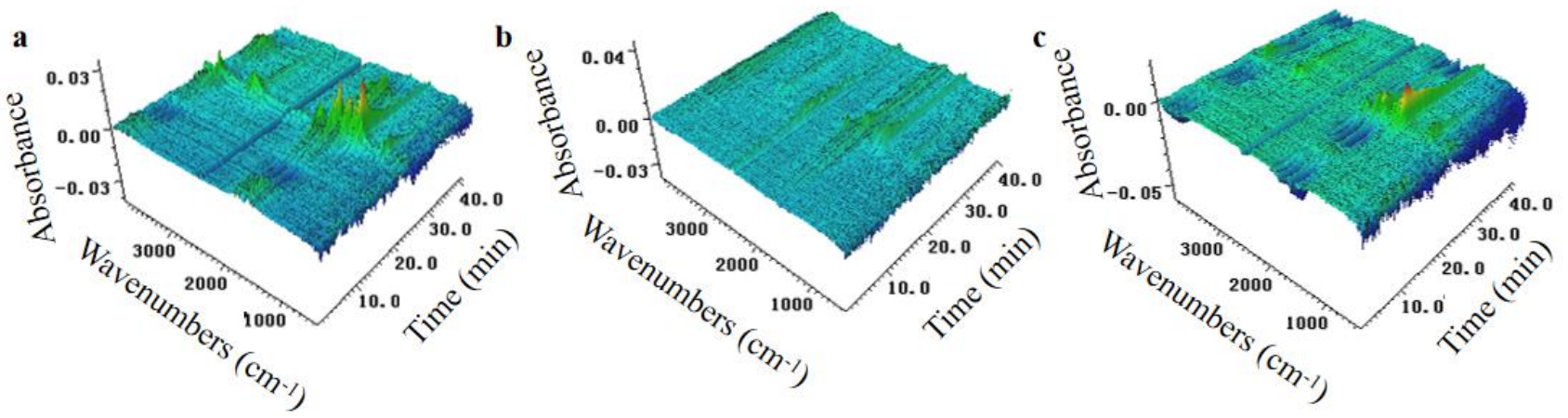

Figure 11. TG-IR spectra of thermal degradation products of EP/DDS (a), EP/DDS/HPCP/9 (b), and EP/DDS/HPCP$6 / \mathrm{H}-\mathrm{U}-3$ (c).
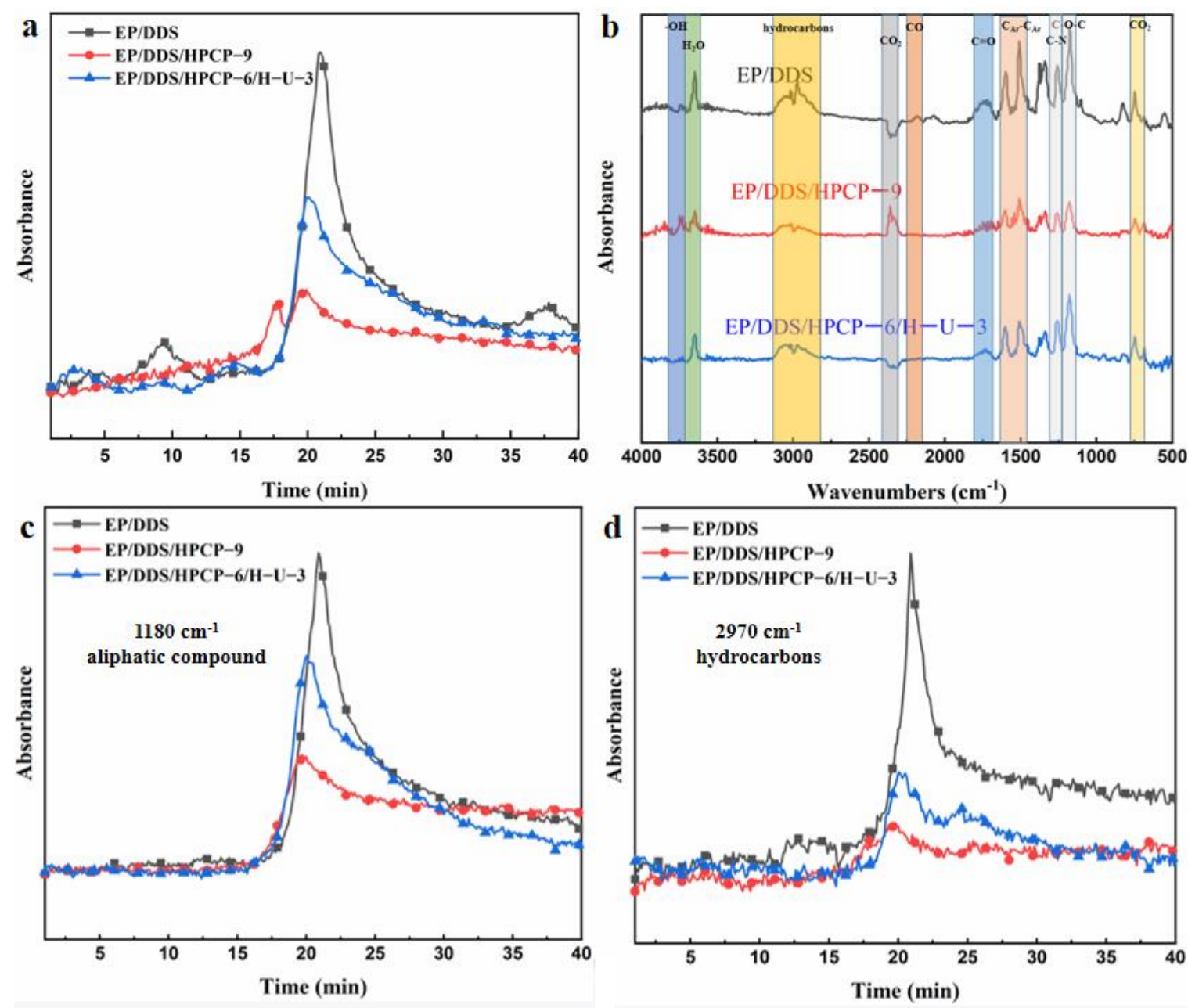

Figure 12. TG-IR spectra of decomposition products of EP composites: total absorbance (a), $T_{\max }(\mathbf{b})$, aliphatic compound (c), and hydrocarbons (d). 

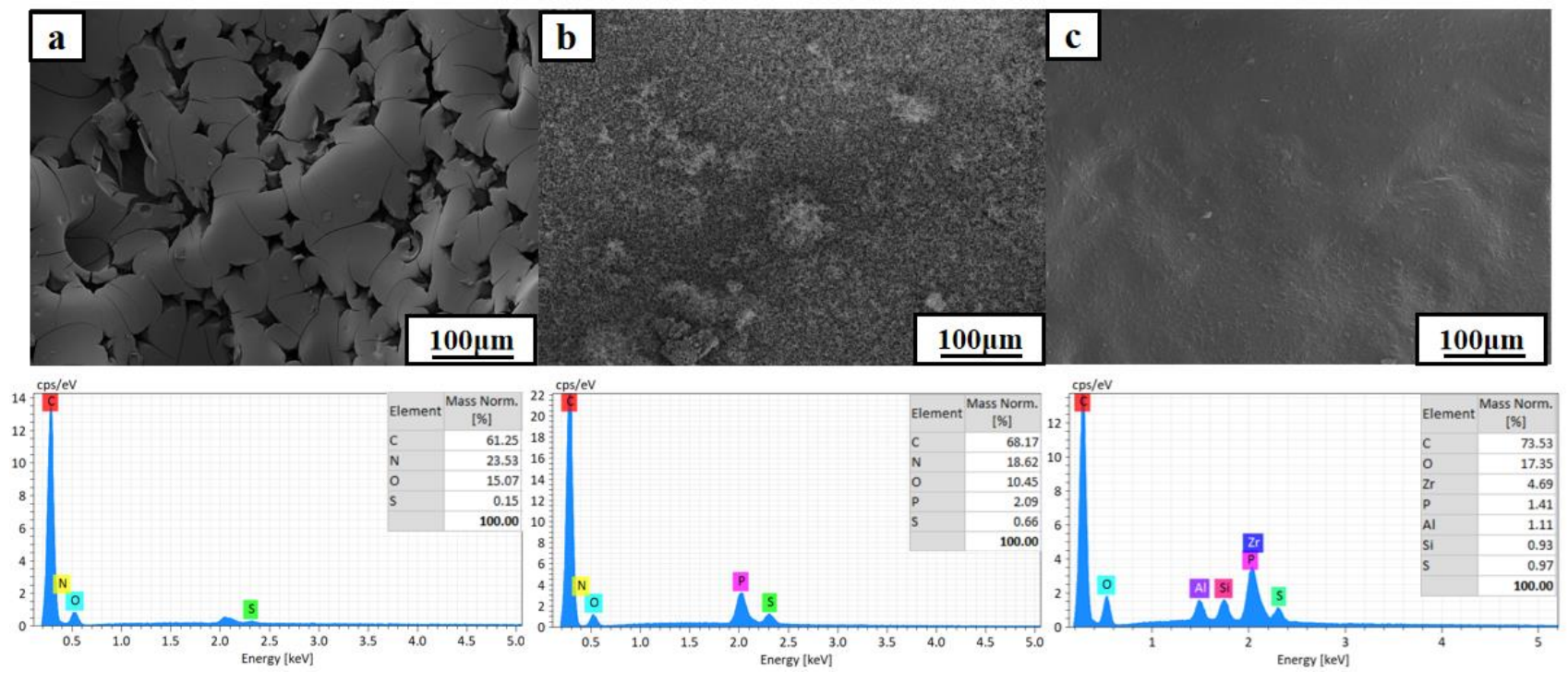

Figure 13. The SEM images and EDS spectra of char residues of EP/DDS (a), EP/DDS/HPCP-9 (b), and EP/DDS/HPCP6/H-U-3 (c) after cone calorimeter tests.

\section{Conclusions}

In this study, $\mathrm{H}-\mathrm{U}$ was synthesized via hydrothermal reaction by combining UiO66$\mathrm{NH}_{2}$ with HNT-COOH, which was used as a novel synergistic flame retardant of HPCP for EP. The introduction of $\mathrm{H}-\mathrm{U}$ can effectively improve the thermostability, tensile and fluxural properties. Additionally, due to improved thermal resistance and the formation of a dense char, EP/DDS/HPCP-6/H-U-3 reached a V-0 rating in UL-94 test and achieved a limited oxygen index of $35.2 \%$. However, the height of the char layer of the EP/DDS/HPCP/H-U samples was reduced due to the introduction of $\mathrm{H}-\mathrm{U}$, weakening their flame-retardant performances in the cone calorimeter test.

Author Contributions: Conceptualization, J.J., S.H. and S.R.; methodology, J.J.,Z.F.,Y.Z. and H.Y.; software, J.J. and S.H.; validation, H.Y. and S.R.; formal analysis, J.J., S.H. and H.Y.; investigation, J.J., Y.Z. and C.Y.; resources, H.Y. and S.R.; data curation, J.J., S.H., H.Y. and S.R.; writing-originaldraft preparation, J.J.; writing — review and editing, S.H., H.Y. and S.R.; visualization, Y.Z. and C.Y.; super vision, S.H. and H.Y.; project administration, J.J.; funding acquisition, Z.F. and S.R. All authors have read and agreed to the published version of the manuscript.

Funding: This research was supported by National Natural Science Foundation of China (No. 51991355) and China Postdoctoral Science Foundation (No. 2021M692759).

Institutional Review Board Statement: Not applicable.

Informed Consent Statement: Not applicable.

Data Availability Statement: All data is offered by corresponding author for reasonable request.

Conflicts of Interest: The authors declare no conflict of interest.

\section{References}

1. Huo, S.; Liu, Z.; Wang, J. Thermal properties and flame retardancy of an intumescent flame-retarded epoxy system containing phosphaphenanthrene, triazine-trione and piperidine. J. Therm. Anal. Calorim. 2019, 139, 1099-1110. [CrossRef]

2. Jin, F.-L.; Li, X.; Park, S.-J. Synthesis and application of epoxy resins: A review. J. Ind. Eng. Chem. 2015, 29, 1-11. [CrossRef]

3. Gergely, A.; Bertóti, I.; Török, T.; Pfeifer, É.; Kálmán, E. Corrosion protection with zinc-rich epoxy paint coatings embedded with various amounts of highly dispersed polypyrrole-deposited alumina monohydrate particles. Prog. Org. Coat. 2013, 76, 17-32. [CrossRef]

4. Azeez, A.A.; Rhee, K.Y.; Park, S.J.; Hui, D. Epoxy clay nanocomposites-processing, properties and applications: A review. Compos. Part B Eng. 2013, 45, 308-320. [CrossRef] 
5. Huo, S.; Yang, S.; Wang, J.; Cheng, J.; Zhang, Q.; Hu, Y.; Ding, G.; Zhang, Q.; Song, P.; Wang, H. A Liquid PhosphaphenanthreneDerived Imidazole for Improved Flame Retardancy and Smoke Suppression of Epoxy Resin. Acs Appl. Polym. Mater. 2020, 2, 3566-3575. [CrossRef]

6. Rakotomalala, M.; Wagner, S.; Doring, M. Recent Developments in Halogen Free Flame Retardants for Epoxy Resins for Electrical and Electronic Applications. Materials 2010, 3, 4300-4327. [CrossRef] [PubMed]

7. Fang, F.; Ran, S.; Fang, Z.; Song, P.; Wang, H. Improved flame resistance and thermo-mechanical properties of epoxy resin nanocomposites from functionalized graphene oxide via self-assembly in water. Compos. Part B Eng. 2019, 165, 406-416. [CrossRef]

8. Wang, X.; Hu, Y.; Song, L.; Xing, W.; Lu, H.; Lv, P.; Jie, G. Flame retardancy and thermal degradation mechanism of epoxy resin composites based on a DOPO substituted organophosphorus oligomer. Polymer 2010, 51, 2435-2445. [CrossRef]

9. Ran, L.; Wang, X. Synthesis, characterization, thermal properties and flame retardancy of a novel nonflammable phosphazenebased epoxy resin. Polym. Degrad. Stab. 2009, 94, 617-624. [CrossRef]

10. Peng, W.; Lei, C.A.; Hang, X.A.; Tz, A. Nitrogen/sulfur-containing DOPO based oligomer for highly efficient flame-retardant epoxy resin-ScienceDirect. Polym. Degrad. Stab. 2020, 171. [CrossRef]

11. Lligadas, G.; Ronda, J.C.; Galià, M.; Cádiz, V. Synthesis and properties of thermosetting polymers from a phosphorous-containing fatty acid derivative. J. Polym. Sci. Part A Polym. Chem. 2006, 44, 5630-5644. [CrossRef]

12. Zhang, K.; Shen, M.M.; Wu, K.; Liu, H.F.; Zhang, Y. Comparative study on flame retardancy and thermal degradation of phosphorus- and silicon-containing epoxy resin composites. J. Polym. Res. 2011, 18, 2061-2070. [CrossRef]

13. Liu, J.; Dai, J.; Wang, S.; Peng, Y.; Cao, L.; Liu, X. Facile synthesis of bio-based reactive flame retardant from vanillin and guaiacol for epoxy resin-ScienceDirect. Compos. Part B Eng. 2020, 190. [CrossRef]

14. Huo, S.; Song, P.; Yu, B.; Ran, S.; Chevali, V.S.; Liu, L.; Fang, Z.; Wang, H. Phosphorus-containing flame retardant epoxy thermosets: Recent advances and future perspectives. Prog. Polym. Sci. 2021, 114. [CrossRef]

15. Huo, S.; Yang, S.; Wang, J.; Cheng, J.; Zhang, Q.; Hu, Y.; Ding, G.; Zhang, Q.; Song, P. A liquid phosphorus-containing imidazole derivative as flame-retardant curing agent for epoxy resin with enhanced thermal latency, mechanical, and flame-retardant performances. J. Hazard Mater. 2020, 386, 121984. [CrossRef]

16. Qian, L.-J.; Ye, L.-J.; Xu, G.-Z.; Liu, J.; Guo, J.-Q. The non-halogen flame retardant epoxy resin based on a novel compound with phosphaphenanthrene and cyclotriphosphazene double functional groups. Polym. Degrad. Stab. 2011, 96, 1118-1124. [CrossRef]

17. Huang, X.; Wei, W.; Wei, H.; Li, Y.; Gu, X.; Tang, X. Preparation of heat-moisture resistant epoxy resin based on phosphazene. J. Appl. Polym. Sci. 2013, 130, 248-255. [CrossRef]

18. Yang, S.; Wang, J.; Huo, S.; Wang, M.; Wang, J.; Zhang, B. Synergistic flame-retardant effect of expandable graphite and phosphorus-containing compounds for epoxy resin: Strong bonding of different carbon residues. Polym. Degrad. Stab. 2016, 128, 89-98. [CrossRef]

19. García, F.J.; García Rodríguez, S.; Kalytta, A.; Reller, A. Study of Natural Halloysite from the Dragon Mine, Utah (USA). Z. Anorg. Allg. Chem. 2009, 635, 790-795. [CrossRef]

20. Lvov, Y.; Wang, W.; Zhang, L.; Fakhrullin, R. Halloysite Clay Nanotubes for Loading and Sustained Release of Functional Compounds. Adv. Mater. 2016, 28, 1227-1250. [CrossRef]

21. Zhi, L.; Liu, L.; Alejandro, J.G.; Wang, D.Y. Bioinspired polydopamine-induced assembly of ultrafine Fe(OH)3 nanoparticles on halloysite toward highly efficient fire retardancy of epoxy resin via an action of interfacial catalysis. Polym. Chem. 2017, 8 , 3926-3936. [CrossRef]

22. Brondani, D.; Scheeren, C.W.; Dupont, J.; Vieira, I.C. Halloysite clay nanotubes and platinum nanoparticles dispersed in ionic liquid applied in the development of a catecholamine biosensor. Analyst 2012, 137, 3732-3739. [CrossRef] [PubMed]

23. Mukai, M.; Ma, W.; Ideta, K.; Takahara], A. Preparation and characterization of boronic acid- functionalized halloysite nanotube/poly(vinyl alcohol) nanocomposites. Polymer 2019, 178. [CrossRef]

24. Du, M.; Guo, B.; Jia, D. Thermal stability and flame retardant effects of halloysite nanotubes on poly (propylene). Eur. Polym. J. 2006, 42, 1362-1369. [CrossRef]

25. Wu, F.; Zheng, J.; Ou, X.; Liu, M. Two in One: Modified Polyurethane Foams by DipDip nanotuf Halloysite Nanotubes with Acceptable Flame Retardancy and Absorbency. Macromol. Mater. Eng. 2019, 304. [CrossRef]

26. Lecouvet, B.; Sclavons, M.; Bailly, C.; Bourbigot, S. A comprehensive study of the synergistic flame retardant mechanisms of halloysite in intumescent polypropylene. Polym. Degrad. Stab. 2013, 98, 2268-2281. [CrossRef]

27. Furukawa, H.; Cordova, K.E.; O'Keeffe, M.; Yaghi, O.M. The Chemistry and Applications of Metal-Organic Frameworks. Science 2013, 341, 1230444. [CrossRef]

28. Li, S.; Yang, K.; Tian, C.; Huang, X.; Huang, W.; Zhang, H. Preparation and applications of novel composites composed of metal-organic frameworks and two-dimensional materials. Chem. Commun. 2016, 52, 1555-15562. [CrossRef]

29. Gopalsamy, K.; Prakash, M.; Kumar, R.M.; Subramaman, V. Density functional studies on the hydrogen storage capacity of boranes and alanes based cages. Int. J. Hydrog. Energy 2012, 37, 9730-9741. [CrossRef]

30. Morozan, A.; Jaouen, F. Metal organic frameworks for electrochemical applications. Energy Environ. Sci. 2012, 5, 9269-9290. [CrossRef]

31. Rocca, J.D.; Liu, D.; Lin, W. Nanoscale Metal-Organic Frameworks for Biomedical Imaging and Drug Delivery. Acc. Chem. Res. 2011, 44, 957-968. [CrossRef] 
32. Sai, T.; Ran, S.; Guo, Z.; Yan, H.; Zhang, Y.; Song, P.; Zhang, T.; Wang, H.; Fang, Z. Deposition growth of Zr-based MOFs on cerium phenylphosphonate lamella towards enhanced thermal stability and fire safety of polycarbonate. Compos. Part B-Eng. 2020, 197. [CrossRef]

33. Hou, Y.; Hu, W.; Gui, Z.; Hu, Y. A novel Co(II)-based metal-organic framework with phosphorus-containing structure: Build for enhancing fire safety of epoxy. Compos. Sci. Technol. 2017, 152, 231-242. [CrossRef]

34. Zhang, J.; Li, Z.; Zhang, L.; Yang, Y.; Wang, D.-Y. Green Synthesis of Biomass Phytic Acid-Functionalized UiO-66-NH2 Hierarchical Hybrids toward Fire Safety of Epoxy Resin. Acs Sustain. Chem. Eng. 2020, 8, 994-1003. [CrossRef]

35. Liu, M.; Chang, Y.; Yang, J.; You, Y.; He, R.; Chen, T.; Zhou, C. Functionalized halloysite nanotube by chitosan grafting for drug delivery of curcumin to achieve enhanced anticancer efficacy. J. Mater. Chem. B 2016, 4, 2253-2263. [CrossRef] [PubMed]

36. Sai, T.; Ran, S.; Guo, Z.; Fang, Z. A Zr-based metal organic frameworks towards improving fire safety and thermal stability of polycarbonate. Compos. Part B Eng. 2019, 176. [CrossRef]

37. Yang, S.; Huo, S.; Wang, J.; Zhang, B.; Wang, J.; Ran, S.; Fang, Z.; Song, P.; Wang, H. A highly fire-safe and smoke-suppressive single-component epoxy resin with switchable curing temperature and rapid curing rate. Compos. Part B Eng. $2021,207$. [CrossRef]

38. Yano, K.; Usuki, A.; Okada, A. Synthesis and properties of polyimide-clay hybrid films. J. Polym. Sci. Part A Polym. Chem. 1997, 35, 2289-2294. [CrossRef]

39. Liu, M.X.; Guo, B.C.; Du, M.L.; Cai, X.J.; Jia, D.M. Properties of halloysite nanotube-epoxy resin hybrids and the interfacial reactions in the systems. Nanotechnology 2007, 18, 9. [CrossRef]

40. Cavka, J.H.; Jakobsen, S.; Olsbye, U.; Guillou, N.; Lillerud, K.P. A New Zirconium Inorganic Building Brick Forming Metal Organic Frameworks with Exceptional Stability. J. Am. Chem. Soc. 2008, 130, 13850-13851. [CrossRef]

41. Yu, B.; Xing, W.; Guo, W.; Qiu, S.; Wang, X.; Lo, S.; Hu, Y. Thermal exfoliation of hexagonal boron nitride for effective enhancements on thermal stability, flame retardancy and smoke suppression of epoxy resin nanocomposites via sol-gel process. J. Mater. Chem. A 2016, 4, 7330-7340. [CrossRef]

42. Huo, S.; Zhou, Z.; Jiang, J.; Sai, T.; Ran, S.; Fang, Z.; Song, P.; Wang, H. Flame-retardant, transparent, mechanically-strong and tough epoxy resin enabled by high-efficiency multifunctional boron-based polyphosphonamide. Chem. Eng. J. 2022, 427. [CrossRef]

43. Koerner, H.; Misra, D.; Tan, A.; Drummy, L.; Mirau, P. Montmorillonite-thermoset nanocomposites via cryo-compounding. Polymer 2006, 47, 3426-3435. [CrossRef]

44. Bugnicourt, E.; Galy, J.; Gérard, J.; Boué, F.; Barthel, H. Structural investigations of pyrogenic silica-epoxy composites: Combining small-angle neutron scattering and transmission electron microscopy. Polymer 2007, 48, 949-958. [CrossRef]

45. Ye, Y.; Chen, H.; Wu, J.; Ye, L. High impact strength epoxy nanocomposites with natural nanotubes. Polymer 2007, 48, 6426-6433. [CrossRef]

46. Ramezanzadeh, M.; Tati, A.; Bahlakeh, G.; Ramezanzadeh, B. Construction of an epoxy composite coating with exceptional thermo-mechanical properties using Zr-based NH2-UiO-66 metal-organic framework (MOF): Experimental and DFT-D theoretical explorations. Chem. Eng. J. 2021, 408. [CrossRef] 